\title{
Enamel Renal Syndrome with Genu Valgum: A rare case report.
}

\author{
Dr. N. Kavitha .M.D.S. \\ (Senior Assistant Professor, Government Dharmapuri Medical College And Hospital, Dharmapuri-636701, \\ Tamilnadu, India.)
}

\begin{abstract}
Rare association of hypo plastic Amelogenesis Imperfecta with Nephrocalcinosis is otherwise called Enamel Renal Syndrome. And its association with Genu Valgum (knock knee) is extremely rare. This paper explains about the clinicopathological features of a 7 year old female baby with yellow to brown discolored, pitted, corroded appearance of all her primary and permanent teeth came for her dental management, turned out to be diagnosed as having Enamel Renal Syndrome. Which was further complicated with knock knee. Thus patients with amelogenesis Imperfecta should also be considered for evaluation of Enamel Renal Syndrome.
\end{abstract}

Keywords: Amelogenesis imperfecta, Enamel Renal Syndrome, Nephrocalcinosis, Rickets, Bedwetting.

\section{Introduction}

Enamel Renal Syndrome (ERS) is also known by various synonyms such as MacGibbon syndrome, Lubinsky syndrome, and Lubinsky-MacGibbon syndrome. It is characterized by enamel agenesis and medullary nephrocalcinosis ${ }^{1}$

Although few cases of Amelogenesis Imperfecta (AI) and nephrocalcinosis syndrome ${ }^{2-14}$ and with distal bending of forearm has been reported ${ }^{14}$, but Enamel Renal syndrome association with Genu valgum (knock knee) secondary to rickets is very rare and not reported so far.

Amelogenesis imperfecta is a heterogeneous group of conditions, genomic in origin, which affects the structure and clinical appearance of the enamel of all or nearly all the teeth in a more or less equal manner and which may be associated with morphologic or biochemical changes elsewhere in the body ${ }^{15}$. Autosomal dominant, autosomal recessive, and X-linked modes of inheritance have also been reported. In general, the defects in AI may be classified as hypo plastic, hypo calcified, or hypo maturation types, depending on the stage of enamel formation that is primarily affected ${ }^{15}$.

This paper explains about the clinicopathological features of a 7 year old female baby with yellow to brown discolored, pitted, corroded appearance of all her primary and permanent teeth came for her dental management, tured out to be diagnosed as having AI and Nephrocalcinosis. Syndrome further complicated with Genu valgum

Purpose of this article is to understand Amelogenesis Imperfecta acts as a marker in early diagnosis of this rare syndrome that would help in early intervention of disease progression, improve the quality of life and reduce rate of renal detoriation.

\section{Case history}

7 years old female patient came with the complaints of pain, food impaction between her left upper back teeth. Her history revealed she was born to a healthy consanguineous parents and she has one healthy elder brother. She gave the history of frequent urination at day time and bedwetting at night, increased thrust of water and occasionally abdominal pain. On Clinical examination, ectomorphically built, short stature, under nourished child with Waddling gait. She was not able to stand straight without support and her knees were knocking each other. Clinically no chest deformities and frontal bossing .

On intra oral examination, she had totally 22 teeth, except her exfoliated upper deciduous centrals including 4 permanent molars. Her teeth were yellow to yellowish brown colour with varying degrees of rough irregular pitted, corroded surfaces present. All of her primary and permanent teeth are affected. Her permanent molars followed by primary molars are severely affected than primary anterior teeth. Literally no enamel was present on the newly erupted all the permanent $1^{\text {st }}$ molars. With disto-occlusal caries in all primary molars (fig$1)$.

Since the patient was living in endemic fluorosis area, Clinically diagnosed as type I diabetes mellitus/rickets/ Genu valgum with Amelogenesis imperfect/Dental fluorosis was made. Fluorosis was ruled out in biochemical investigation, which showed drinking water fluoride $1.1 \mathrm{mg} / \mathrm{l}$ and urine fluoride $0.1 \mathrm{mg} / \mathrm{l}$.

Patient was sent for Abdominal Ultra sound scan, revealed multiple calcific specks noted in medulla of both the kidneys. Imaging features suggestive of Bilatral medullary Nephrocalcinosis (fig-2). 
Radiographic examination showed normal eruption pattern and teeth with thin radio opaque dentine layer over broad pulp chambers with no enamel layer otherwise no distinct density differences between enamel and dentine seen. This features suggestive of hypoplastic type of Amelogenesis Imperfecta (fig-3).

$\mathrm{x}$ - ray limbs showed metaphysical frying and cupping of distal ulnar and radius (fig-4) and knock knees(fig-5). Her hematological findings were within normal limits. She had normal serum blood sugar, urea, creatinine. But serum alkaline phosphatase increased $934 \mathrm{U} / \mathrm{L}$, decreased serum calcium $7.9 \mathrm{mg} / \mathrm{dl}$, normal serum electrolytes with reduced 25-hydroxy cholecalciferol vitamin D 10.5ng/mi. Features suggestive of vitamin D deficiency state.

\section{Discussion}

Although AI occurs not only in AI and nephrocalcinosis syndrome also in amelo-onycho-hypohidrotic syndrome, Morquio syndrome, Kohlschutter syndrome, tricho-dento-osseous syndrome, AI with taurodontism syndrome, oculo-dento-osseous dysplasia, epidermolysis bullosa hereditaria ${ }^{15}$.Two hypothesis is suggested for this combination of AI and nephrocalcinosis. First hypothesis suggests that there is an abnormality in the interstitial matrix, which leads to dystrophic calcification in the kidney and abnormal enamel production in the teeth $^{3}$. Another hypothesis suggests that many of the dental proteins that were believed to be tissue specific may be expressed in more than one dental tissue and also in non-dental tissues and the role of these proteins in calcium and phosphate metabolism.

Similarly, nephrocalcinosis is common feature of genetically determined disorders with hypercalciuria, such as Dent disease, Bartter syndrome and X-linked hypophosphataemia. However, no case has been reported with those diseases combined with AI. It should further be noted that hypercalciuria is not the only reason for nephrocalcinosis in ERS, because some sibling cases have shown hypocalciuria ${ }^{3,5,6}$. Untreated nephrocalcinosis is known to be associated with significant morbidity, some cases progressed to renal insufficiency ${ }^{2,3,6}$ and other cases featured certain renal tubular disorders such as hypocalciuria ${ }^{3,5,6}$ or urinary concentration disability ${ }^{3}$. Patient's family who had this syndrome was not detected until they were well into adulthood, with recurrent urinary infections, pyelonephritis, or renal colic and the passage of renal stone ${ }^{14}$.

Genetic analyses identified novel FAM20A Mutations Associated with Enamel Renal Syndrome ${ }^{16}$. Orodental clinical features typical of FAM20A recessive mutations include generalized thin hypo plastic or absent enamel, primary and permanent teeth affected, flat cusps on posterior teeth, relative microdontia and spaced teeth, intra-pulpal calcifications, delayed tooth eruption, impacted posterior teeth with hyperplastic follicle (hamartoma-like) and altered eruption pathway, root dilacerations of impacted teeth, gingival fibromatosis (variable severity), gingival and dental follicle ectopic calcification on biopsies. Additional features that may be observed include semi-lunar shape of central incisor edge, crown resorption of non-erupted teeth, anterior open-bite, root hypercementosis and inter-radicular dentine dysplasia, supernumerary teeth ${ }^{17}$.

During the early years of childhood, genu valgum and genu varum are common concerns for parents. These problems represent normal physiologic variations in most children. However, a few children will experience pathologic lower extremity mal-alignment leading to cosmetic and functional deficits. Although many exist, the most frequent causes of pathologic genu varum and genu valgum are Blount's disease and renal rickets, respectively ${ }^{18}$. Genu valgum is typically associated with renal osteodystrophy because the onset of chronic renal disease generally occurs while children are in the valgus phase. Metabolic conditions such as rickets affect the entire epiphyseal plate ${ }^{18}$ like our present case. Rickets is a softening of bones in children due to deficiency or impaired metabolism of vitamin D, magnesium, phosphorus or calcium, potentially leading to fractures and deformity. Treatment of genu valgum and genu varum includes observation for the lesser deformities, bracing for moderate deformities and surgical correction for the excessive deformities ${ }^{19}$.

\section{Figures:}
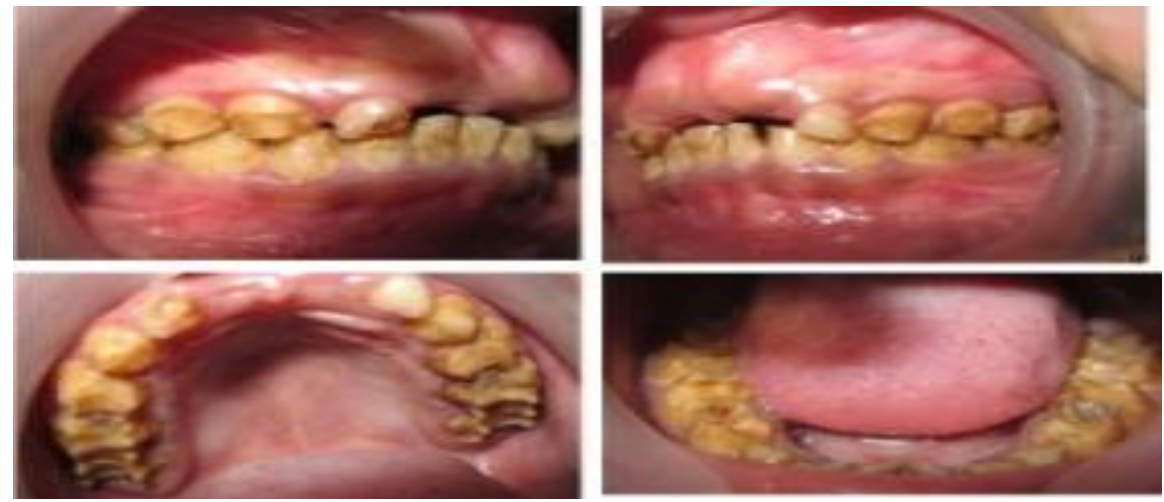

Fig: 1 Intra oral view yellow to yellowish brown colour rough, irregular, pitted surface of teeth. 

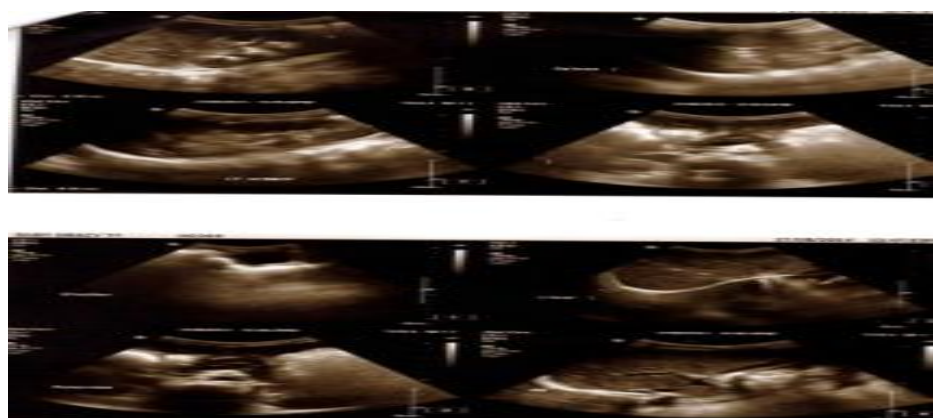

Fig: 2 USG abdomen shows Bilateral medullary Nephrocalcinosis.

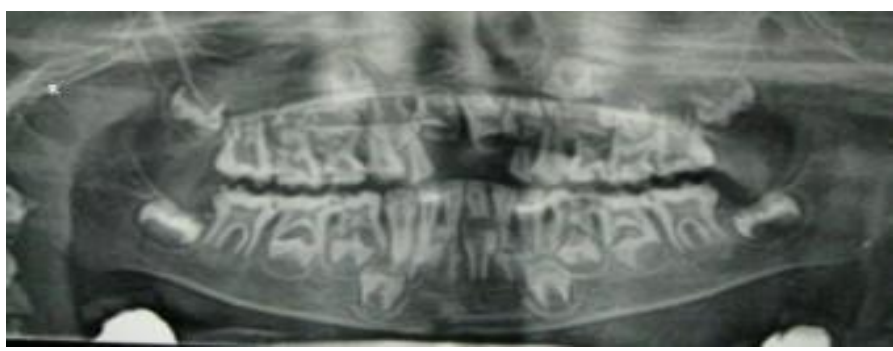

Fig: 3 Orthopantamogram shows enamel agenesis.

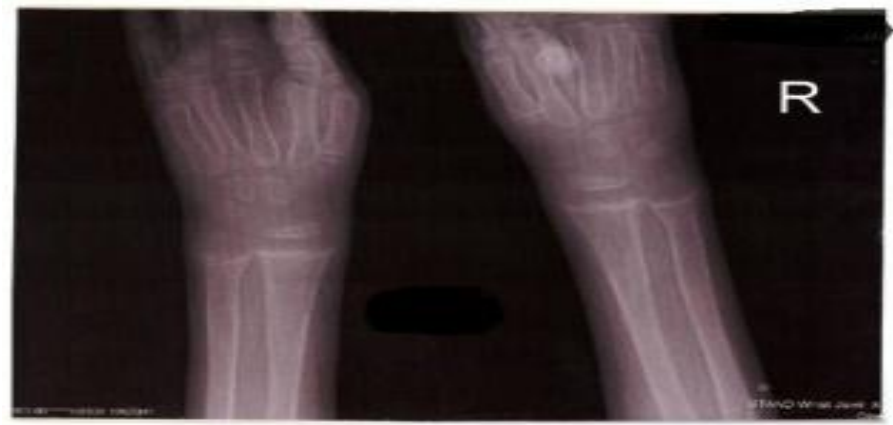

Fig: 4 Hand wrists X-ray shows frying and cupping of distal ulnar and radius.

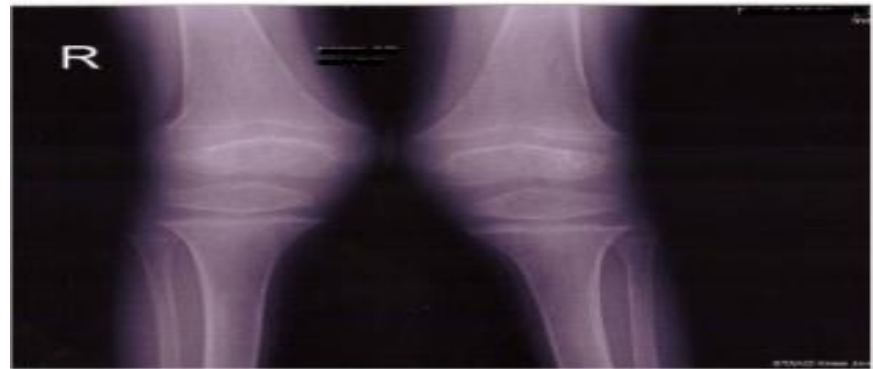

Fig :5 X ray Lower limb reveals knock knees.

\section{Conclusion}

By concluding that children with apparently autosomal recessive Amelogenesis Imperfecta with frequent bedwetting habit and knock knees should not be neglected, at least, they should undergo a renal ultrasound examination to rule out any renal pathology. So AI acts as marker for early identification of Enamel Renal Syndrome and referral of these patients to concerned specialist would help in early intervention of disease progression, improve the quality of life and reduce the morbidity associated with renal function impairment and renal failure. Further studies required to know the genetic defects, phenotypic differences and true burden of the disease.

\section{Acknowledgement}

I would like to acknowledge Dr.Shregalatha.MDS, Dr.A.Ramkumar.MDS and all the medical professional people GDMCH, Dpi-1 who had helped in the management of this child. 


\section{References}

[1]. Kala Vani S V, Varsha M, Sankar Y U. Enamel renal syndrome: A rare case report. J Indian Soc Pedod Prev Dent. 2012;30:169-72.

[2]. MacGibbon D. Generalized enamel hypoplasia and renal dysfunction. Aust Dent J. 1972;17:61-3.

[3]. Lubinsky M, Angle C, Marsh PW, Witkop CJ., Jr Syndrome of amelogenesis imperfecta, nephrocalcinosis, impaired renal concentration, and possible abnormality of calcium metabolism. Am J Med Genet. 1985;20:233-43.

[4]. Hall RK, Phakey P, Palamara J, McCredie DA. Amelogenesis imperfecta and nephrocalcinosis syndrome. Case studies of clinical features and ultrastructure of tooth enamel in two siblings. Oral Surg Oral Med Oral Pathol Oral Radiol Endod. 1995;79:583-92.

[5]. Dellow EL, Harley KE, Unwin RJ, Wrong O, Winter GB, Parkins BJ. Amelogenesis imperfecta, nephrocalcinosis, and hypocalciuria syndrome in two siblings from a large family with consanguineous parents. Nephrol Dial Transplant. 1998;13:31936.

[6]. Normand de la Tranchade I, Bonarek H, Marteau JM, Boileau MJ, Nancy J. Amelogenesis imperfecta and nephrocalcinosis: A new case of this rare syndrome. J Clin Pediatr Dent. 2003;27:171-5.

[7]. Paula LM, Melo NS, Silva Guerra EN, Mestrinho DH, Acevedo AC. Case report of a rare syndrome associating amelogenesis imperfecta and nephrocalcinosis in a consanguineous family. Arch Oral Biol. 2005;50:237-42.

[8]. Fu XJ, Nozu K, Goji K, Ikeda K, Kamioka I, Fujita T, et al. Enamel-renal syndrome associated with hypokalaemic metabolic alkalosis and impaired renal concentration: A novel syndrome?Nephrol Dial Transplant. 2006;21:2959-62.

[9]. Hunter L, Addy LD, Knox J, Drage N. Is amelogenesis imperfecta an indication for renal examination? Int J Paediatr Dent.2007;17:62-5.

[10]. Elizabeth J, Lakshmi Priya E, Umadevi KM, Ranganathan K. Amelogenesis imperfecta with renal disease - A report of two cases.J Oral Pathol Med. 2007;36:625-8.

[11]. Kirzioglu Z, Ulu KG, Sezer MT, Yüksel S. The relationship of amelogenesis imperfecta and nephrocalcinosis syndrome. Med Oral Patol Oral Cir Bucal. 2009;14:e579-82.

[12]. Martelli-Júnior H, dos Santos Neto PE, de Aquino SN, de Oliveira Santos CC, Borges SP, Oliveira EA, et al. Amelogenesis imperfecta and nephrocalcinosis syndrome: A case report and review of the literature. Nephron Physiol. 2011;118:p62-5.

[13]. Rajathi J M, Austin RD, Mathew P. McGibbon Syndrome ; A report of three siblings. Indian J Dent Res 2013;24;511-4.

[14]. Patel A, Jagtap C, Bhat C, and Shah R. Bilateral nephrocalcinosis and amelogenesis imperfecta: A case report. Contemp Clin Dent. 2015;6:262-265.

[15]. Aldred MJ, Savarirayan R, Crawford PJ. Amelogenesis imperfecta: A classification and catalogue for the 21 st century. Oral Dis. 2003;9:19-23.

[16]. Wang SK, Reid BM, Dugan SL, et al. FAM20A Mutations Associated with Enamel Renal Syndrome. Journal of Dental Research. 2014;93(1):42-48

[17]. De la Dure-Molla M, Quentric M, Yamaguti PM, et al. Pathognomonic oral profile of Enamel Renal Syndrome (ERS) caused by recessive FAM20Amutations. Orphanet Journal of Rare Diseases. 2014;9:84.

[18]. Rakesh N. Bahadure, Nilima Thosar, Ritika Kriplani, Sudhindra Baliga, and Punit Fulzel. Dental Aspect of Distal Tubular Renal Acidosis with Genu Valgum Secondary to Rickets: A Case Report. Case Reports in Dentistry.vol. 2012, Article ID 374945, 4 pages, 2012.

[19]. Hensinger.R.N. Angular deformities of the lower limbs in children. Iowa Orthopaedic Journal, 1089; 9:16-24, 1989. 